\title{
Erratum to: The earth system model of intermediate complexity CLIMBER-3 $\alpha$. Part I: description and performance for present-day conditions
}

\author{
Marisa Montoya - Alexa Griesel • Anders Levermann • \\ Juliette Mignot $\cdot$ Matthias Hofmann • \\ Andrey Ganopolski $\cdot$ Stefan Rahmstorf
}

Published online: 7 November 2009

(C) Springer-Verlag 2009

\section{Erratum to: Clim Dyn (2005) 25:237-263 DOI 10.1007/s00382-005-0044-1}

In Montoya et al. (2005) the atmospheric component of CLIMBER-3 $\alpha$ was stated to be the same as in CLIMBER-2, albeit with finer resolution. Accidentally, we missed to report on two further simplifications that were made during the development process:

1. Advection of heat and moisture was simplified such that deviations of the geostrophic wind from their zonal average were neglected.

2. Thermal wind was neglected in the advection of temperature (Eq. 25 in Petoukhov et al. 2000), just as

The online version of the original article can be found under doi:10.1007/s00382-005-0044-1.

M. Montoya ( $\square)$

Dpto. Astrofísica y Ciencias de la Atmósfera,

Facultad de Ciencias Físicas, Universidad Complutense de

Madrid, Ciudad Universitaria, 28040 Madrid, Spain

e-mail: mmontoya@fis.ucm.es

\section{A. Griesel}

Scripps Institution of Oceanography, University of California San Diego, La Jolla, USA

\author{
A. Levermann · S. Rahmstorf \\ Earth System Analysis, Potsdam Institute for Climate Impact \\ Research and Institute of Physics, \\ Potsdam University, Potsdam, Germany \\ J. Mignot \\ IPSL/LOCEAN, UPMC/CNRS/IRD/MNHN, Paris, France
}

M. Hofmann · A. Ganopolski

Earth System Analysis, Potsdam Institute for Climate Impact

Research, PIK, Potsdam, Germany

\begin{abstract}
is usually done in CLIMBER-2 for the advection of moisture (Eq. 32 in Petoukhov et al. 2000). As a consequence, the advection of moisture and heat is effectively performed by the zonally averaged geostrophic winds plus their ageostrophic component.
\end{abstract}

The reason for these simplifications is that the assumptions underlying these terms cannot be considered valid for the higher atmospheric resolution used in CLIMBER-3 $\alpha$. While including the full representation of the atmospheric dynamics as in CLIMBER-2 has no significant effect on the zonally averaged atmospheric fields, it impacts negatively their horizontal distribution and the associated moisture transport.

CLIMBER-3 $\alpha$ thus comprises the basic dynamical structure of the large-scale atmospheric circulation, especially the zonally averaged geostrophic circulation (including Hadley and Ferrel cells) and the zonal ageostrophic winds (including trade winds).

\section{References}

Montoya M, Griesel A, Levermann A, Mignot J, Hofmann M, Ganopolski A, Rahmstorf S (2005) The Earth system model of intermediate complexity CLIMBER-3 $\alpha$. Part I: description and performance for present day conditions. Clim Dyn 25:237-263

Petoukhov V, Ganopolski A, Brovkin V, Claussen M, Eliseev A, Kubatzki C, Rahmstorf S (2000) CLIMBER-2: a climate system model of intermediate complexity. Part I: model description and performance for present climate. Clim Dyn 16:1-17 